\title{
Aus der Redaktion
}

Cover-Contest 2014

\section{Das sind die besten}

\section{Vielen Dank ...}

... an alle, die per E-Mail oder auf www.facebook.de/thiemeliebtphysiotherapeuten das schönste Cover 2014 gekürt haben.

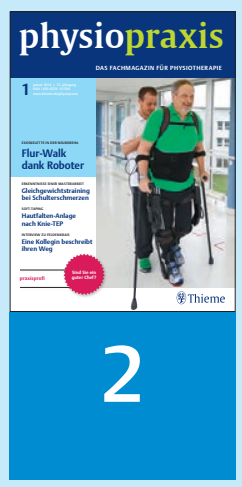

\section{physiopraxis}
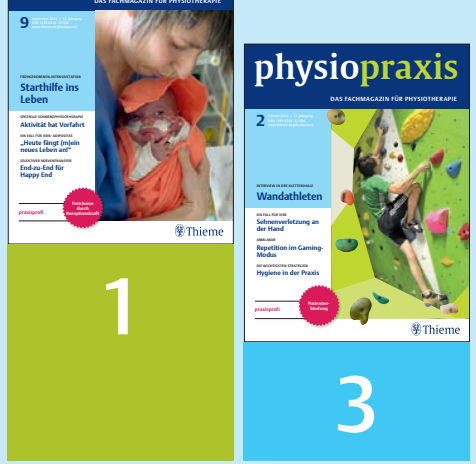

THIEME E-JOURNALS

\section{Das Artikelarchiv von physiopraxis}

Wer lieber elektronisch liest oder bereits erschienene Artikel sucht, ist im Artikelarchiv der physiopraxis richtig. Dort stehen für Sie alle Beiträge, Literaturverzeichnisse und Zusatzmaterialien zum Herunterladen bereit. Gehen Sie dazu einfach ins Internet zu www.thieme-connect.de/products/ physiopraxis.

Auf der Startseite unseres Artikelarchivs präsentieren wir Ihnen immer die aktuelle Ausgabe.

Über die Menüpunkte links unter dem Titelbild kommen Sie über

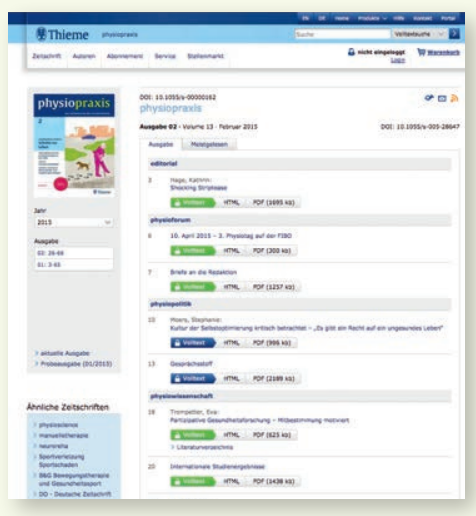
die Jahreszahl und die Wahl der gewünschten Ausgabe zu den einzelnen Ausgaben und Artikeln.

Wer auf der Suche nach einem bestimmten Beitrag oder Thema ist, wird über die Volltextsuche rechts oben fündig.

Reinschauen lohnt sich. In unserem Artikelarchiv wartet ein Fundus aus knapp sieben Jahren ergopraxis auf Sie.

\section{SCHREIBEN SIE UNS}

\section{Ihre Meinung zählt}

Ihre Anregungen sind willkommen: physiopraxis@thieme.de. Wir behalten uns vor, die Briefe zu kürzen. Die Texte spiegeln die Meinung des Verfassers wider und nicht die der Redaktion.
PHYSIOPRAXIS ALS APP

\section{Für Apple und Android!}

Unsere Abonnenten können sich jede Ausgabe als App kostenlos downloaden und gelangen so direkt zu allen Zusatzinfos von physiopraxis. Dafür müssen Sie einfach von Google Play oder beim Apple Store die App laden und nach dem Öffnen unter den „Einstellungen“ die Abonummer eintragen. Im Anschluss lässt sich die Ausgabe herunterladen. Die Abonummer sind die 6-7 Ziffern auf dem Adressetikett.

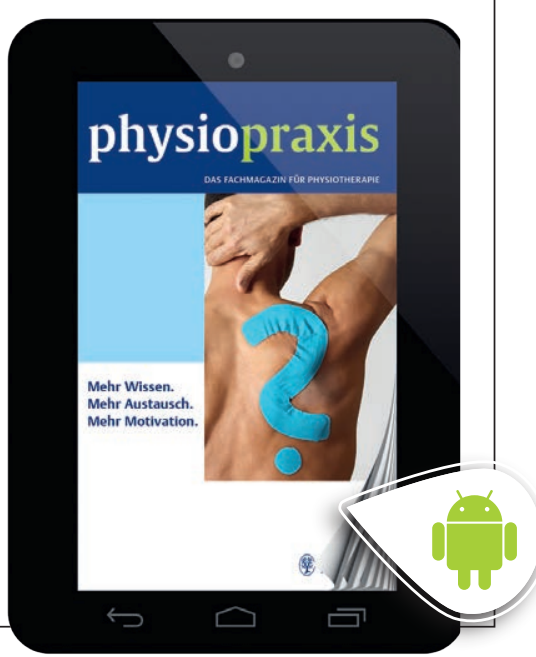

